Article

\title{
Sedimentation of Raw Sewage: Investigations For a Pumping Station in Northern Germany under Energy-Efficient Pump Control
}

\author{
Martin Rinas *, Jens Tränckner and Thilo Koegst \\ Department of Water Management, University of Rostock, Satower Straße 48, 18059 Rostock, Germany; \\ jens.traenckner@uni-rostock.de (J.T.); t.koegst@stalums.mv-regierung.de (T.K.) \\ * Correspondence: martin.rinas@uni-rostock.de
}

Received: 30 November 2018; Accepted: 24 December 2018; Published: 26 December 2018

\begin{abstract}
Flow control in wastewater pressure pipes can reduce energy consumption but increases the risk of sediment formation due to reduced flow velocity. In this work, the sedimentation behavior of dry and wet weather samples at the inflow of a wastewater pumping station is determined by settling column experiments. Based on the derived characteristic settling velocity $\left(v_{s}\right)$ distribution, the impact of energy-efficient flow control on sediment formation in pressure pipes (600 $\mathrm{mm}$ diameter) was quantified in comparison to a simple on/off operation. In parallel, the sediment formation for 2 years of pumping operation was monitored indirectly via the friction losses. For the investigated case, settling is strongly influenced by the inflow condition (dry, combined from road runoff). Under combined inflow, the proportion of solids with $v_{s}$ from 0.007 to $1.43 \mathrm{~mm} / \mathrm{s}$ significantly increases. In energy-efficient mode with smoother operation and shorter switch-off sequences, the sediment formation is significant lower. The mean deposit's height in energy-efficient control was calculated to $0.137 \mathrm{~m}$, while in on/off operation the mean deposit's height was $0.174 \mathrm{~m}$. No disadvantages arise over a long period by installing the energy-efficient control. The decreased flow lead under the investigated conditions even to a reduced sediment formation.
\end{abstract}

Keywords: sewage sedimentation; sediment formation; deposit's height; settling velocity experiment; energy-efficiency; pressure pipe

\section{Introduction}

Sewage transport in urban drainage systems involves in many cases the use of pumping stations (PS). Pumps are usually designed to handle maximum design inflow, which rarely occurs under normal operating conditions. Typically, a PS is operated in a simple switch-on/switch-off mode. While the pump sump is filled with sewage the pump switches on at a defined level before overflow occurs and switches off before it runs dry (two-point control). For most inflow conditions, pump flow exceeds by far the actual demand, resulting in unnecessary friction losses and consequently in a high energy consumption.

The key of a minimized energy demand is the reduction of friction losses, resulting from low flow velocities and engendered lower shear stress in connected pressure pipes. To increase efficiency and minimize energy demand, sewage PS can be equipped with frequency control. Combined with an intelligent, rule-based control strategy, significant energy savings can be achieved [1]. Identified side effects are the reduction of operation and maintenance costs and an expected increased durability of pumping aggregates, armatures, and electric engines due to smoother operation conditions.

A benefit of a typical two-point control lies in its high design flow, as recommended flow velocities to avoid sedimentation risks are ensured in switch-on mode (e.g., in Germany a flow velocity of 0.6 to 
$1.2 \mathrm{~m} / \mathrm{s}$ inside a pressure pipe system at least once per day, [2]). The challenge in energy optimization of pumping stations is therefore to consider recommended flow velocities to avoid sedimentation risks and minimize energy demand in parallel. Hence, there is a trade-off between minimization of energy consumption and safe sewage transport avoiding blockage.

For good reasons operators of PS evaluate the safe sewage transportation higher than possible energy savings. By feeling, most operators assume that switch-on/switch-off mode is less risky with regard to sediment formation. But this estimation suffers from: (i) unknown knowledge of the actual settling behavior of local sewer and (ii) missing information about the occurrence of settling processes inside the pumping system. Hence, detailed information of both parts helps to control those systems in an efficient and reliable way. Applied correctly, the presented information in this article helps to increase the efficiency of the sewerage systems regarding energy optimization and sediment transport at once.

Sediments in sewers have for decades been the subject of many investigations, mainly focusing on combined systems. Many experimental procedures to determine settling behavior of sewage are proposed, with different pros and cons. Starting with investigations on combined sewer overflow events [3], several experiments and methods have been developed to understand and describe sedimentation processes in sewer systems (e.g., [4-7]). The original driver has often been the assessment of particle bound pollution transport in combined sewer systems (e.g., [8]) or storm water systems (e.g., $[9,10])$. The underlying principle of those activities is to determine particle mass fractions of different settling velocity classes by laboratory experiments (ex situ), mainly performed in settling columns (also used for river sediments, e.g., by [11]). In situ devices are trying to define the settling velocities for individual or specific types of particles, e.g., by image analysis of synthetic spheres [12], by optical backscatter sensors for sediment flocs [13], or fine-grained sediments of estuaries [14].

Theoretical work is trying to describe the settling process by models (e.g., the effect of lift forces on the settling behavior by [15]) or equations for the settling velocity of particles and sediments [16-18]. Often, experimental data of settling experiments are processed by fitting a sigmoidal logistic function $M(t)$ [19-21]. After fitting three parameters $b, c$, and $d$ within the $M(t)$ function, settling velocity curves $F\left(v_{s}\right)$ enable a continuous description of accumulated mass fraction as function of the respective settling velocity.

The foremost objective of this article is to minimize energy demand in operation of a PS without risking unintended sediment formation in connected pressure pipes. How flow control influences this system is a priori hardly predictable, since lower flow velocities increase sedimentation risk while shorter pump pauses reduce it. This work contributes to this subject by addressing the following aspects:

- Investigation of the settling behavior of typical raw sewage at the inflow side of an urban influenced PS;

- Evaluation of the modification of the settling behavior by wet weather inflow (road runoff);

- Calculation of the sediment formation inside the connected pressure pipe in (i) two-point control and (ii) energy-efficient control; and

- Verification by determining the deposit's height inside the pressure pipe by a daily observation of the pipe curve.

\section{Materials and Methods}

\subsection{Pumping Station, Control Modes, and Monitoring}

\subsubsection{Pumping Station}

The studied PS "Rostock-Schmarl" is located in the city of Rostock in northern Germany. The PS is mainly influenced by untreated domestic sewage $(\approx 40,000$ inhabitants $)$ combined with industrial/commercial wastewater (hotels, shipyards, local municipal utility, cruise ships). Although 
main roads runoff is also connected to the PS, it is part of the separate sewerage system in Rostock (roof runoff is discharged into a storm water system). Under dry weather conditions, pure sewage is transported, with its specific particle characteristics (low density, no ideal sphere form of particles; flocculate-matter and synthetic material as a mixture; particle interferences; sewage composition changes permanently). The connected separate sewerage system sums up to $80 \mathrm{~km}$. The PS is equipped with a rake on the inflow side (space bar opening of $20 \mathrm{~mm}$ ) to retain large obstacles. The sewage is transported in two parallel pipelines (cast iron, diameter $=600 \mathrm{~mm}$, length $=4100 \mathrm{~m}$ ) by four pumps, each with a power of $55 \mathrm{~kW}$, to the central wastewater treatment plant (wwtp) in Rostock.

\subsubsection{Two-Point Control}

The usual operation mode of PS Rostock-Schmarl is a typical two-point control strategy in which pumps switch on and off at defined water levels inside the sump. The PS is equipped with a frequency drive to balance the feed to the wwtp. By this, mains frequency is reduced from $50 \mathrm{~Hz}$ to $43 \mathrm{~Hz}$. Accordingly, power input, engine speed, flow and friction losses are reduced, so next to the balanced feed, energy savings can already be achieved by the two-point control. The key aspects of this control strategy are shown in Table 1.

Table 1. Key aspects of pump control modes for pumping stations (PS) Rostock-Schmarl.

\begin{tabular}{|c|c|c|c|c|c|c|c|}
\hline \multirow{3}{*}{$\begin{array}{l}\text { Control } \\
\text { Strategy }\end{array}$} & \multirow{3}{*}{$\begin{array}{c}\text { On-Level } \\
\text { (m) }\end{array}$} & \multirow{3}{*}{$\begin{array}{c}\text { Off-Level } \\
(\mathrm{m})\end{array}$} & \multirow{3}{*}{$\begin{array}{c}\begin{array}{c}\text { Operation at } \\
\text { Frequency }\end{array} \\
(\mathrm{Hz})\end{array}$} & \multirow{3}{*}{$\begin{array}{c}\text { Soft Start } \\
\text { Duration } \\
\text { (s) }\end{array}$} & \multicolumn{2}{|c|}{ Duty Point } & \multirow{3}{*}{ Control Rules } \\
\hline & & & & & $\mathbf{Q}$ & $\mathbf{H}$ & \\
\hline & & & & & $(1 / s)$ & (m) & \\
\hline $\begin{array}{c}\text { Two-Point } \\
\text { Control }\end{array}$ & 0.8 & 0.4 & $43-45$ & 60 & 130 & 17.8 & transport-rules \\
\hline $\begin{array}{l}\text { Rule-Based } \\
\text { Control }\end{array}$ & 0.8 & 0.4 & $\begin{array}{l}41 \text { (energy } \\
\text { optimum) }\end{array}$ & 60 & 110 & 17.45 & $\begin{array}{c}\text { energy- \& } \\
\text { transport-rules }\end{array}$ \\
\hline
\end{tabular}

\subsubsection{Rule-Based Control}

To achieve further energy savings, a rule-based control strategy was added to the PS for one year. Pumps were controlled by a PC, while the control rules were formulated in Matlab. The rule-based control is explained in detail in [1]. The general idea is to pump only the incoming flow until the energetic minimum (expressed as $\mathrm{kWh}$ per $\mathrm{m}^{3}$ ) is reached. Lower flows (i.e., frequencies and impeller speeds) would lead an increased energy demand because of a decreasing degree of efficiency. In case of lower inflows, the PS operates with the energy optimal flow and shuts off when the sump runs empty. In the case of PS Rostock-Schmarl the energy optimum is reached at $41 \mathrm{~Hz}$.

In a condensed formulation, the following control rules apply:

if water level $>$ shut off level

begin operation mode $=$ "ON"

if inflow > optimal flow

operate at inflow

else

operate at optimal flow

end

else

operation mode $=$ "OFF"

Further restrictions have to be considered for a safe sewage transport (transport-rules): minimum flow rate to open check valves, on-off-level restrictions of sump, empty sump regular, min/max engine speed and minimum flow rate to avoid sedimentation formation, flush pipes regular. Key aspects of the control strategy are shown in Table 1. 


\subsubsection{Monitoring}

To verify the influence of the control modes on energy consumption and sediment formation inside the pressure pipe, 10 parameters were logged over 2 years ( 1 year in each control mode). On the feeding side of the PS: sump level $(\mathrm{m})$ and inflow $(\mathrm{l} / \mathrm{s})$. Regarding the pumping aggregate: power input $(\mathrm{kW})$, frequency $(\mathrm{Hz})$, engine speed $\left(\mathrm{min}^{-1}\right)$, torque $(\mathrm{Nm})$, voltage $(\mathrm{V})$. On the outflow side of the PS: pressure (bar), flow (l/s), TSS (mg/L). Power input, frequency, engine speed, pressure and flow were used in this work for the investigation of sediment formation inside the pressure pipe.

\subsection{Sampling and Experimental Procedure}

\subsubsection{Sampling}

Altogether, 21 dry- and wet-weather samples were collected from the inflow channel of PS "Rostock-Schmarl", during the rule-based control mode period. By this, raw sewage, under dry weather conditions, as well as, combined sewage with road runoff, was collected. Immediately after the samples were taken from the middle of the feed channel (1200 $\mathrm{mm}$ diameter) with a ladle, the initial particle concentration (analysis according to [22] by filtration and weight loss) was determined and the settling experiment started.

Table 2 shows two selected samples including sampling time, sampling volume, initial total suspended solids $\left(T S S_{r e f}\right)$ and related precipitation data.

Table 2. Characteristics of selected dry- and wet-weather examples.

\begin{tabular}{ccccc}
\hline Sample & $\begin{array}{c}\text { Sampling } \\
\text { Time }\end{array}$ & $\begin{array}{c}\text { Sampling } \\
\text { Volume (L) }\end{array}$ & TSS $_{\text {ref }}(\mathbf{m g} / \mathrm{L})$ & Remarks \\
\hline dry & $10: 00$ & 30 & 390.2 & $\begin{array}{c}\text { Dry weather inflow } \\
\text { Wet }\end{array}$ \\
$13: 00$ & 30 & 544.8 & $\begin{array}{c}\text { Weather inflow: Precipitation } \\
\text { height }=10.1 \mathrm{~mm} / \mathrm{d}\end{array}$ \\
\hline
\end{tabular}

The selected dry weather example is representative for a maximum daily inflow under dry weather conditions, while the wet weather example represents a nominal inflow, influenced by a rain event with a long duration and changing intensity. The rain events were measured by a weather station of the German Weather Service (DWD) located inside the catchment area.

\subsubsection{Experimental Design and Procedure}

The experimental setup and post-processing of data should provide a reasonable compromise between applicability in operational practice, reproducibility and expressiveness concerning the sedimentation characteristics of a distinct raw sewage sample. After a thorough literature review, two methods were combined to determine the settling behavior of the collected samples. The experimental setup follows the VICPOL protocol [8]. The process itself is simple and the experimental conditions are comparable to real world conditions in stagnant pressure tubes. For the subsequent data processing, the related VICAS protocol [23] was applied to describe the distribution of settling velocities in the sample as continuous mathematical function.

Figure 1 shows a schematic view (similar to [8]) and a photo of the construction. The VICPOL protocol determines $n$ mass fractions with their specific settling velocity $v_{S}(\mathrm{~mm} / \mathrm{s})$, by dividing the sewage sample into $n$ sub-samples with $n$ settling times. The choice of the best suitable settling times varies with sewage characteristics. After several pre-tests, a time range between $15 \mathrm{~s}$ and $24 \mathrm{~h}$ settling was found to cover the expectable range of settling velocities (Table 3), tending to smaller intervals at the beginning, according to the high settling dynamics of wet weather samples. 


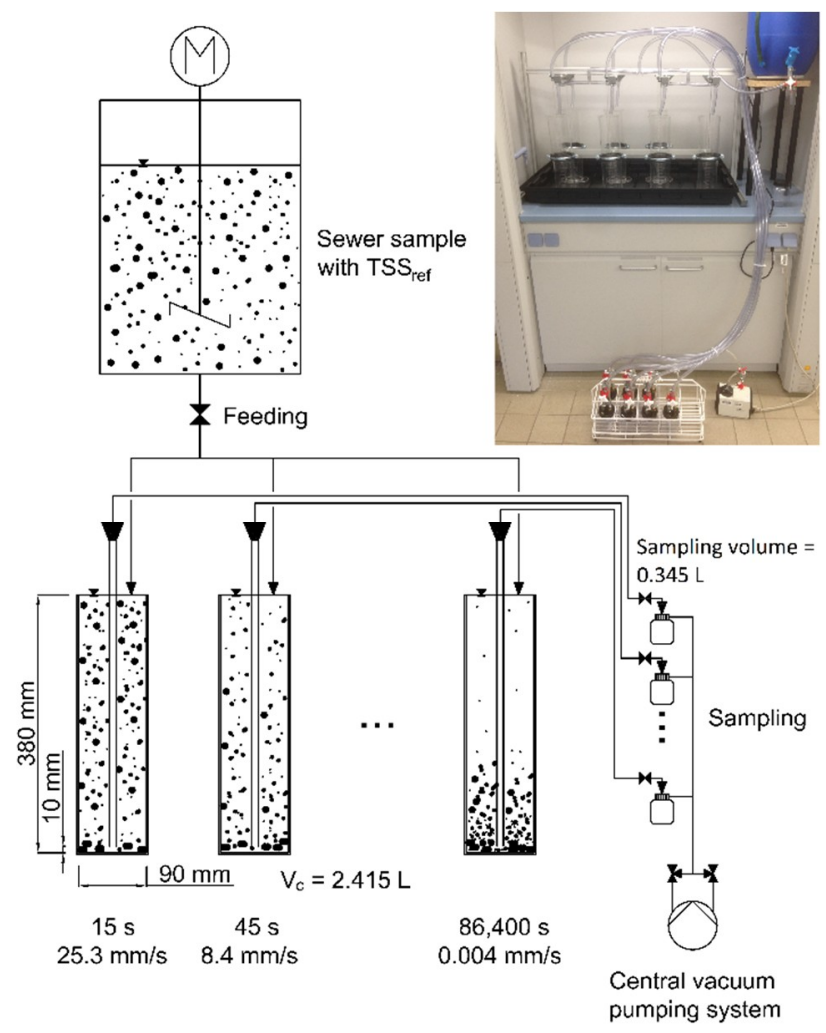

Figure 1. Designed and constructed experimental setup for settling measurement of raw sewage at University of Rostock.

Table 3. Settings for settling tests.

\begin{tabular}{ccccccccc}
\hline Column & $\boldsymbol{i}$ & $\mathbf{1}$ & $\mathbf{2}$ & $\mathbf{3}$ & $\mathbf{4}$ & $\mathbf{5}$ & $\mathbf{6}$ & $\mathbf{7}$ \\
\hline Settling Duration $\boldsymbol{t}$ & $\mathbf{( s )}$ & 15 & 45 & 180 & 420 & 1800 & 14,400 & 86,400 \\
\hline Settling Velocity $\boldsymbol{v}_{\boldsymbol{s}}\left(\boldsymbol{H}_{\boldsymbol{c}} / \boldsymbol{t}\right)$ & $(\mathbf{m m} / \mathbf{s})$ & 25.3 & 8.4 & 2.1 & 0.9 & 0.2 & 0.026 & 0.004 \\
\hline
\end{tabular}

The experiment itself is processed within 3 main steps:

1. Filling tank and columns: Storage tank is filled with the sewage sample from the PS (30 L). 7 settling columns (each volume $V_{c}=2.415 \mathrm{~L}$, height $H_{c}=380 \mathrm{~mm}$ ) are filled subsequently via separate tubes by gravity from tank till overflow. Settling starts immediately.

2. Settling: Parallel settling in all 7 columns until the specific settling duration $t$ reached.

3. Sampling and TSS analysis: After the specific settling duration $t$, a sample (volume $=0.345 \mathrm{~L}$ ) is extracted from the bottom of the respective column $i$ and analysed for TSS. The samples were extracted using a central vacuum pump, connected to a $10 \mathrm{~mm}$ glass tube, ending $10 \mathrm{~mm}$ above columns bottom.

The execution of settling experiments generate TSS and additional chemical parameters from the original sample and from the seven settling columns. The sampling volume $(0.345 \mathrm{~L})$ multiplied by seven (columns) equals to a total column volume of $2.415 \mathrm{~L}$. The total reference particle mass of each column $i,\left(T S S_{\text {ref }}\right.$ multiplied by $\left.V_{c}\right)$ must correspond to the sum of the $\triangle T S S_{i}\left(T_{S} S_{i}\right.$ minus TSS $\left.i-1\right)$ of each column $i$ multiplied by sampling volume (100\% settling assumed), see Equation (1). This relationship is helpful to define the required maximal settling time and for error evaluation.

$$
\sum_{i=1}^{n} \Delta \operatorname{TSS}_{i}\left(\frac{m g}{L}\right) \cdot 0.345(L) \leq \operatorname{TSS}_{r e f}\left(\frac{m g}{L}\right) \cdot 2.415(L)=\text { total particle mass }(m g)
$$


If the relationship from Equation (1) is true, the TSS data is numerically adjusted to a sigmoid function $M(t)$ (Equation (2), [21]), according to method 2 of the VICAS protocol [23]. The fitted $M(t)$ function, a description of the cumulative growth of the settled mass, leads to the $S(t)$ function in Equation (3), the cumulative growth minus the pre-settled mass. Finally, the $S(t)$ function is transferred into the settling velocity curve $F\left(v_{s}\right)$, Equation (4), describing the cumulative settling velocity distribution.

$$
\begin{gathered}
M(t)=S(t)+t \frac{d M(t)}{d t}=\frac{b}{1+\left(\frac{c}{t}\right)^{d}} \\
S(t)=M(t)-t \frac{d M(t)}{d t}=\frac{b\left(1+(1-d)\left(\frac{c}{t}\right)^{d}\right)}{\left(1+\left(\frac{c}{t}\right)^{d}\right)^{2}} \\
F\left(v_{s}\right)=100\left(1-\frac{S(t)}{\text { total Mass }}\right)
\end{gathered}
$$

\subsection{Calculation of Sediment Formation and Deposit's Height in the Pressure Pipe}

\subsubsection{Sediment Formation}

The sediment formation in the pressure pipe, called $m_{s}$ (mass settled), is defined as the cumulative settled mass within each switch-off sequence. The settled mass is based on: (i) the settling behavior of the raw sewage expressed by experimentally derived $F\left(v_{s}\right)$ function and (ii) the cumulative settling duration $t_{s}$ during each switch-off sequence. For a comparison of the control modes, the mean cumulative settling duration $\overline{t_{s}}(\mathrm{~s})$ is calculated for all switched-off sequences over the studied period (Equation (5), where $n_{t_{s}}$ is the number of logged data points in each switch-off sequence). A diurnal course of the settling duration inside the pipe is the result.

$$
\overline{t_{s}}=\frac{1}{n_{t_{s}}} \sum_{i=1}^{n_{t_{s}}} t_{s, i}
$$

All mass fractions with a settling velocity $v_{S}(\mathrm{~mm} / \mathrm{s})$ larger than required to pass the pipe diameter within the mean cumulative settling duration $\overline{t_{s}}$ (termed $v_{\text {s, } \text {,ipe, }}$, settling velocity threshold of the pipe), are defined to form sediments. The related mean settled mass $\overline{m_{S}}(\%)$ is calculated using Equation (6).

$$
\overline{m_{S}}\left(\overline{t_{s}}\right)=100-F\left(v_{s, p i p e}\left(\overline{t_{s}}\right)\right)
$$

With $v_{\text {s,pipe, }}$ the settling velocity threshold of the pipe calculated by Equation (7).

$$
v_{s, p i p e}\left(\overline{t_{s}}\right)=\frac{\text { pipe diamter }}{\overline{t_{s}}}
$$

As a result, the mean sediment mass at switch-off mode is derived for each control mode as a mean diurnal course.

\subsubsection{Deposit's Height}

The above described approach simplifies real world conditions and needs to be validated by data of actual sediment formation. However, an integrative deposit height in the pressure pipe cannot be measured directly. Though, an increase of deposit's leads to a reduced cross section which in turn increases friction losses. This relation is used to inversely estimate deposit heights from the pipe curve (pressure height $=f(f l o w)$ ). For this, the cross section of the pipe is split into two segments: (i) the free cross section where water is transported $\left(A_{T}\left(\mathrm{~m}^{2}\right)\right)$ and (ii) the cross section occupied by sediments $\left(A_{s}\left(\mathrm{~m}^{2}\right)\right)$. Applying the geometric relationships of a circle, the area $\left(A_{T}\right)$, wetted perimeter $\left(P_{T}(\mathrm{~m})\right)$ 
(see Figure 2) and hydraulic diameter $\left(D_{T}(\mathrm{~m})\right)$ of free cross section are calculated with Equations (8) to $(10)$.

$$
\begin{aligned}
& A_{T}=\text { Pipe cross section }-A_{s}=\frac{\pi d^{2}}{4}-\frac{d}{4}\left(d \cdot \arccos \left(1-\frac{2 h_{s}}{d}\right)-2 \sqrt{h_{s}\left(d-h_{s}\right)} \cdot\left(1-\frac{2 h_{s}}{d}\right)\right) \\
& P_{T}=\pi \cdot d-P_{s}+w=\pi \cdot d-d \cdot \arccos \left(1-\frac{2 h_{s}}{d}\right)+2 \sqrt{h_{s}\left(d-h_{s}\right)} \\
& D_{T}=\frac{4 \cdot A_{T}}{P_{T}}
\end{aligned}
$$

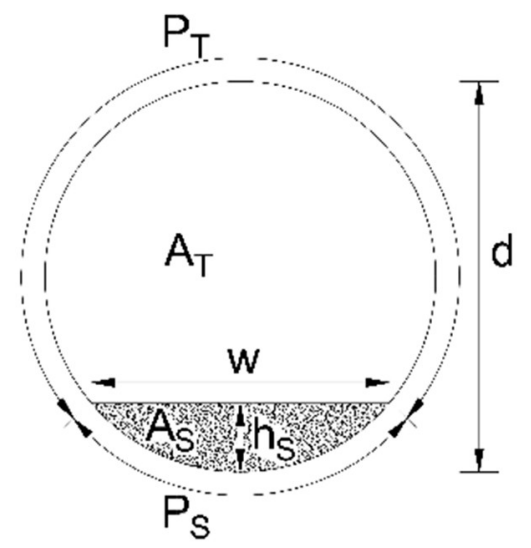

Figure 2. Definition of a pressure pipes geometric parameters for the calculation of the deposit's height, $A_{T}=$ free cross section for transport $\left(\mathrm{m}^{2}\right), A_{s}=$ deposit's cross section $\left(\mathrm{m}^{2}\right), P_{T}=$ wetted perimeter $(\mathrm{m})$, $P_{s}=$ deposit's perimeter $(\mathrm{m}), w=$ deposit's width $(\mathrm{m}), h_{s}=$ deposit's height $(\mathrm{m}), d=$ pipe diameter $(\mathrm{m})$.

The pipe curve was daily acquired by varying the control frequency of the pump to achieve in minimum three $(m=3)$ data sets of flow $\left(Q\left(\mathrm{~m}^{3} / \mathrm{h}\right)\right)$ and related pressure $(H(\mathrm{~m}))$. The data sets were adjusted to a second order polynomic function $\left(H_{A}(Q)\right)$ describing the current pipe curve by Equations (11) to (12), with fitting parameters $a_{0}, a_{1}$ and $a_{2}$.

$$
\begin{gathered}
H_{A}(Q)=a_{0}+a_{1} \cdot Q+a_{2} \cdot Q^{2} \\
\min _{a_{0} a_{1} a_{2}} \sum_{i=1}^{m}\left(H_{i}-H_{A}\left(Q_{i}\right)\right)^{2}
\end{gathered}
$$

In a second step, the deposit height $h_{s}(\mathrm{~m})$ is estimated solving Equation (13).

$$
\min _{h_{s}} \sum_{i=1}^{m}\left(h_{g e o}+h_{r, i}-H_{A}\left(Q_{i}\right)\right)^{2}
$$

With hydraulic head $h_{g e o}(\mathrm{~m})$ and $h_{r, i}(\mathrm{~m})$, the calculated friction loss according to Darcy-Weisbach, by Equation (14).

$$
h_{r}=\left(\lambda \cdot \frac{l}{D_{T}}+\sum_{i} \zeta_{i}\right) \cdot \frac{v^{2}}{2 g}=\left(\lambda \cdot \frac{l}{D_{T}}+\sum_{i} \zeta_{i}\right) \cdot \frac{Q^{2}}{2 g 3600^{2} A_{T}^{2}}
$$

where $\lambda(-)$ is the friction factor (calculated after the Colebrook White equation), $\zeta$ the discharge coefficient (-), pipe length $l(\mathrm{~m})$, hydraulic diameter $D_{T}(\mathrm{~m}), g$ the acceleration due to gravity $\left(\mathrm{m} / \mathrm{s}^{2}\right)$, and $v$ the flow velocity $(\mathrm{m} / \mathrm{s}) . v$ can be replaced by the flow rate $Q\left(\mathrm{~m}^{3} / \mathrm{h}\right)$ and the free cross section for transport $A_{T}\left(\mathrm{~m}^{2}\right)$. 


\section{Results and Discussion}

\subsection{Monitoring the Control Modes}

The results of the continuous monitoring of PS Rostock-Schmarl is shown in Figure 3. A stacked bar graph illustrates the settling and pump duration per day (h), which always sum up to $24 \mathrm{~h}$. The mean daily frequency $(\mathrm{Hz})$ is given as hydrograph, while daily precipitation $P$ is visualised in inverse direction as bars $(\mathrm{mm} / \mathrm{d})$. The sampling dates for the lab scale experiments are indicated.

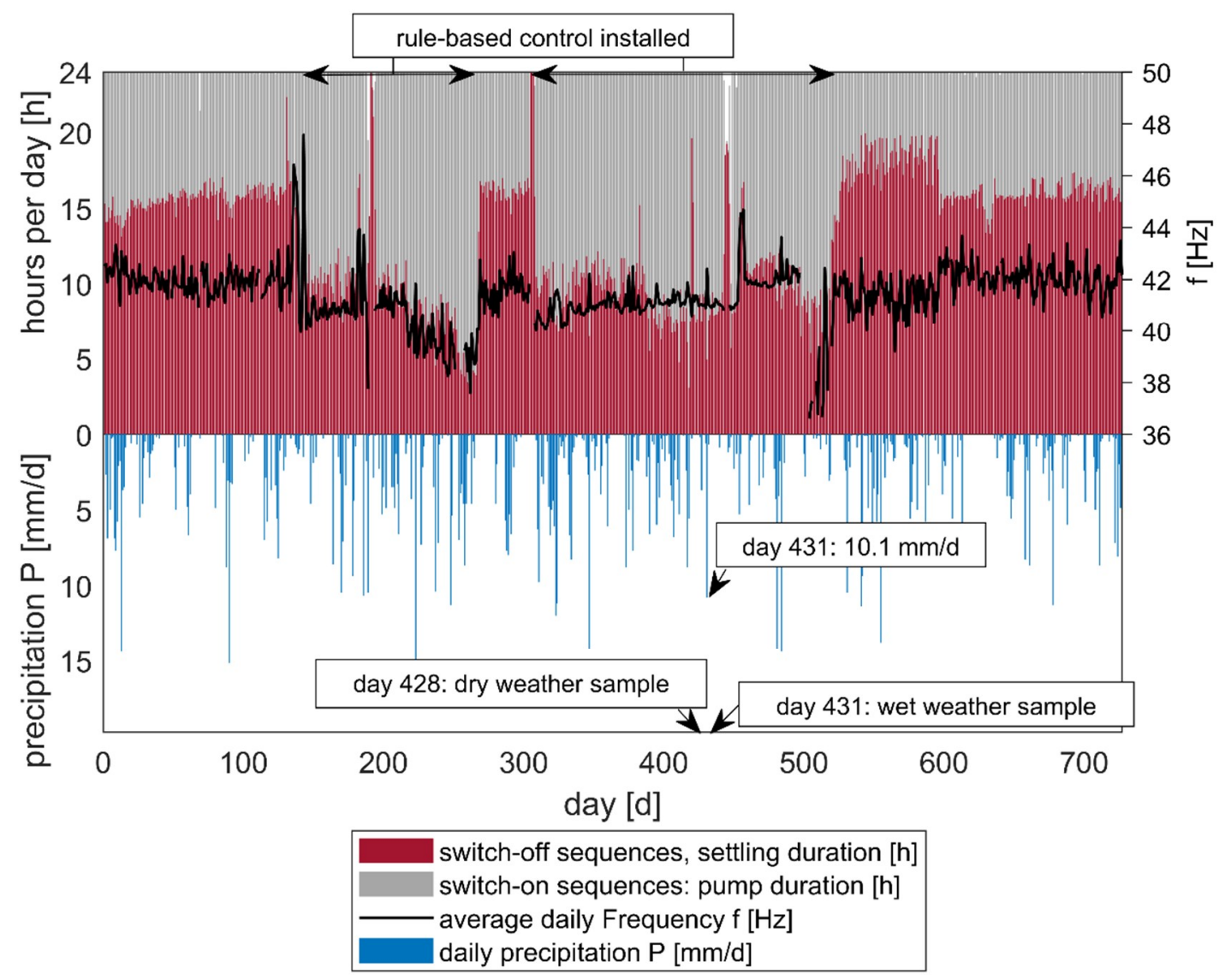

Figure 3. Results after 2 years monitoring PS Rostock-Schmarl: daily settling and pump duration as stacked bar graph, frequency hydrograph and precipitation including marks for sampling dates.

The varying settling and pump duration is a consequence of the control mode and the inflow condition. Pumps, controlled in rule-based mode, are working for longer sequences at the energy optimal frequency of $41 \mathrm{~Hz}$, leading to longer switch-on sequences. Accordingly, the sum of the daily settling duration decreases significantly (average daily settling duration $11.9 \mathrm{~h}$ ). Pumps, controlled in two-point mode, working for shorter sequences in the predefined frequency $(43 \mathrm{~Hz})$. The sum of the daily settling duration increases (average daily settling duration $15 \mathrm{~h}$ ).

Next to the control mode, the pump duration is influenced by the sewage inflow as well. A rainfall event increases the inflow rate (main roads runoff), which leads in both control modes to longer pump sequences. If the inflow is too high, a second pump is switched on automatically (parallel pumping). This, in turn, decreases the pump duration due to higher flow rates. The effect of longer pump sequences is more pronounced in rule-based mode, because of the formulated rule: if inflow > optimal flow, then operate at inflow. This delays parallel operation. In two-point control mode, pumps operate at a constant level until the critical limit is reached. The effect of longer pump sequences is greatly reduced. 
All these effects create the up-and-down course of the settling and pump duration in Figure 3. The average daily frequency hydrograph follows this course. A high frequency in two-point control leads into a maximized settling duration (e.g., $16 \mathrm{~h}$ settling with $44 \mathrm{~Hz}$ frequency on day 631). The same high frequency in rule-based control, leads to a greatly reduced settling duration (only $8.3 \mathrm{~h}$ on day 484).

The effects of a reduced settling potential are: (i) the control rules and (ii) a reduction of the frequency (reduced flow rate). It can therefore be expected, that the significantly reduced settling durations in rule-based control, will lead to less dangerous sediment formation. This becomes evident, regarding the diurnal course of the sedimentation process in combination with the settling properties of the raw sewage.

\subsection{Settling Properties of Dry and Wet Weather Samples}

Sediment formation inside the pipe is, next to the duration of the settling sequences, linked to the settling properties of the transported raw sewage. A fast settling mixture causes sediment problems, even within short settling sequences. With the characterization of the sedimentation behavior based on the explained experimental procedure, a first estimation of the sediment formation in the pipe can be made. The settling behavior of the transported raw sewage for PS Rostock-Schmarl is expressed as settling velocity curves $F\left(v_{s}\right)$. The resulting $F\left(v_{s}\right)$ for dry and wet weather sample (from Table 2), are shown in Figure 4 (line plot). The boxplots indicate the determined settling characteristics of the sewage inflow of PS Rostock-Schmarl due to numerous experiments.
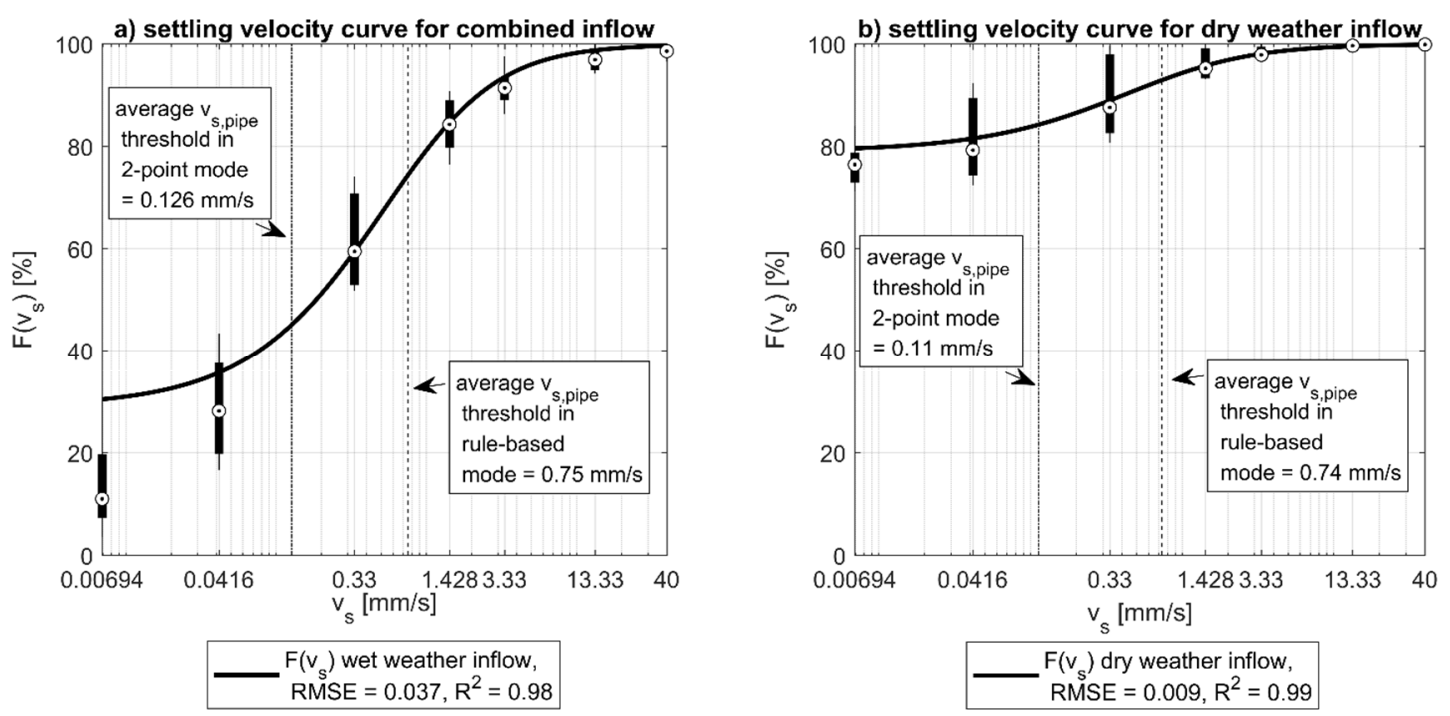

Figure 4. Results for settling measurement of sewage samples from PS Rostock-Schmarl, exemplary settling velocity curves $F\left(v_{s}\right)$ for a wet (a) and dry $(\mathbf{b})$ weather sample including fit results, boxplots with results for all collected samples and average settling velocity thresholds of two-point- and rule-based pump control.

The experimental procedure and subsequent calculation methods are well applicable for both inflow conditions. The $M(t)$ function (Equation (2)), as basis for the $F\left(v_{s}\right)$ curves, is characterized by fitting results with a minimum $\mathrm{R}^{2}$ of 0.98 and a maximum root-mean-square error of 0.037 . This enables well founded statements about the settling characteristics of the raw sewage inflow. An in depth investigation of the experimental procedure, provided by [23], has already shown the applicability to dry- and wet-weather sewage samples as well as the reproducibility of the experimental procedure.

The sewage settling characteristics showing significant differences due to the inflow condition. Settling velocity curves measured for storm water conditions ("wet curves") tend to faster settling. This behavior is well known in the literature $([8,23,24])$. A strict decline was observed from the fourth $(1.43 \mathrm{~mm} / \mathrm{s} \hat{=} 420 \mathrm{~s}$ settling $)$ up to the last measurement $(0.00694 \mathrm{~mm} / \mathrm{s} \hat{=} 24 \mathrm{~h}$ settling). In contrast, 
curves measured for dry weather inflow condition ("dry curves"), tending to gradual decline, with a flattened end at $24 \mathrm{~h}$ settling. This variation in the settling behavior can be lead back to two main reasons: (i) particles washed off (road runoff) and entering the sewer network and (ii) high flow rates (after rain events) inside the feeding channels, spilling particles from wash-off and previously deposited sediments to the PS. In fact, the proportion of each particle (velocity) class changes by a runoff event. Gromaire et al. [8] also mentioned the erosion of deposit's due to higher mobilization in combined flows as a reason for a faster settling of wet weather samples (see also [24]).

Table 4 shows the average proportional change in each $v_{s}$-class, from dry to wet curves. Especially the proportion of particles with $v_{\mathcal{S}}$ from $0.007 \mathrm{~mm} / \mathrm{s}$ up to $1.43 \mathrm{~mm} / \mathrm{s}$ increases (in sum $54.5 \%$ ). It shows, that primarily medium-speed particles were washed off and entered the sewer network. The proportion of particles with $v_{s} \geq 1.43 \mathrm{~mm} / \mathrm{s}$ (fast settling particles) increases only marginally (in sum 10.94\%). The proportion of the slowest particle class decreases drastically (-65.43\%), according to the increase of the medium speed fraction. The key message is here: the particle spectrum did not change from dry- to wet-weather inflow (same $v_{\mathcal{S}}$-classes observed), but rather the proportion of particles, especially in the medium speed fraction.

Table 4. Results for settling measurement of sewage samples from PS Rostock-Schmarl, average change in class proportion from dry to wet samples.

\begin{tabular}{cc}
\hline $\boldsymbol{v}_{s}$ range & $\boldsymbol{F}\left(\boldsymbol{v}_{s}\right)_{\text {wet }}-\boldsymbol{F}\left(\boldsymbol{v}_{s}\right)_{\text {dry }}$ \\
\hline $\mathbf{( m m / s )}$ & $\mathbf{( \% )}$ \\
\hline$v_{s} \geq 40$ & +1.19 \\
$13.3 \leq v_{s} \leq 40$ & +1.55 \\
$3.3 \leq v_{s}<13.3$ & +3.72 \\
$1.43 \leq v_{s}<3.3$ & +4.49 \\
$0.33 \leq v_{S}<1.43$ & +17.19 \\
$0.04 \leq v_{S}<0.33$ & +22.98 \\
$0.007 \leq v_{S}<0.04$ & +14.33 \\
$v_{S}<0.007$ & -65.43 \\
\hline
\end{tabular}

Comparing the $F\left(v_{S}\right)$ curves to the literature $([8,23,24])$, the particulate matter of the collected samples at PS Rostock-Schmarl settles significant slower, regardless to the inflow condition (dry, wet). This might be to design of the PS upstream sewerage system, as a separating sewer but with a main road runoff connected. Typical sewerage systems investigated in the literature are namely combined sewers or storm water systems $([8,9,23,24])$.

To get a first insight into the settling process inside the pressure pipe, the average settling velocity thresholds of the pipe $\left(\overline{v_{\text {s,pipe }}}\right)$, one for each control mode and inflow condition, are shown in Figure 4 (vertical line plots). These were calculated from the overall average settling duration in the switch-off sequences over 2 years monitoring, in rule-based mode to $813 \mathrm{~s}(0.74 \mathrm{~mm} / \mathrm{s}$ respectively) for dry weather inflow and $796 \mathrm{~s}(0.75 \mathrm{~mm} / \mathrm{s}$ respectively) under combined inflow, while in two-point mode to $5454 \mathrm{~s}(0.11 \mathrm{~mm} / \mathrm{s}$ respectively) for dry weather inflow and $4762 \mathrm{~s}(0.126 \mathrm{~mm} / \mathrm{s}$ respectively) under combined inflow. Particle classes with $v_{s} \geq \overline{v_{\text {s,pipe }}}$, settle completely. With all four $\overline{v_{\text {s,pipe }}}$ values lying in the range of the medium speed particle classes, the changed particle composition due to the combined inflow affects the settling processes in both control modes, but significantly reduced in rule-based mode. In rule-based control, higher $\overline{v_{\text {s,pipe }}}$ is the result of the formulated control rules (with pump flow = inflow, $17.13 \mathrm{~h}$ parallel mode in the studied period). Especially for a combined inflow, with pipe flow $=$ inflow, the formulated control rules leading into shorter parallel pumping sequences (in sum $17.13 \mathrm{~h}$ in one year). In two-point control, pumps switch earlier into parallel mode (with pump flow $>>$ inflow, in sum $141.7 \mathrm{~h}$ in one year), resulting in a lower $\overline{v_{\text {s, pipe }}}$ and a high sediment formation potential. Accordingly, a significant reduction in deposit's formation has to be expected for combined inflow, while a slightly change for dry weather inflow is assumed. 


\subsection{Sediment Formation}

An in-depth insight into the pumping process allows well-founded statements about the sediment formation. Detailed pumping data is analyzed with Equation (5). The results are shown in Figure 5 within six single plots, where the left three plots show the results for the rule-based mode and the right three plots the two-point control results. The first row shows the average diurnal course of the settling duration. By the use of Equation (7), this course is transformed into a diurnal course of the settling velocity threshold $v_{s, p i p e}$ (second row). Particle classes with a $v_{s}>$ current $v_{s, p i p e}$ settle completely. Knowing the settling properties of the transported raw sewage $\left(F\left(v_{S}\right)\right)$ leads to the sediment formation profile, using Equation (6), see Figure 5, third row.
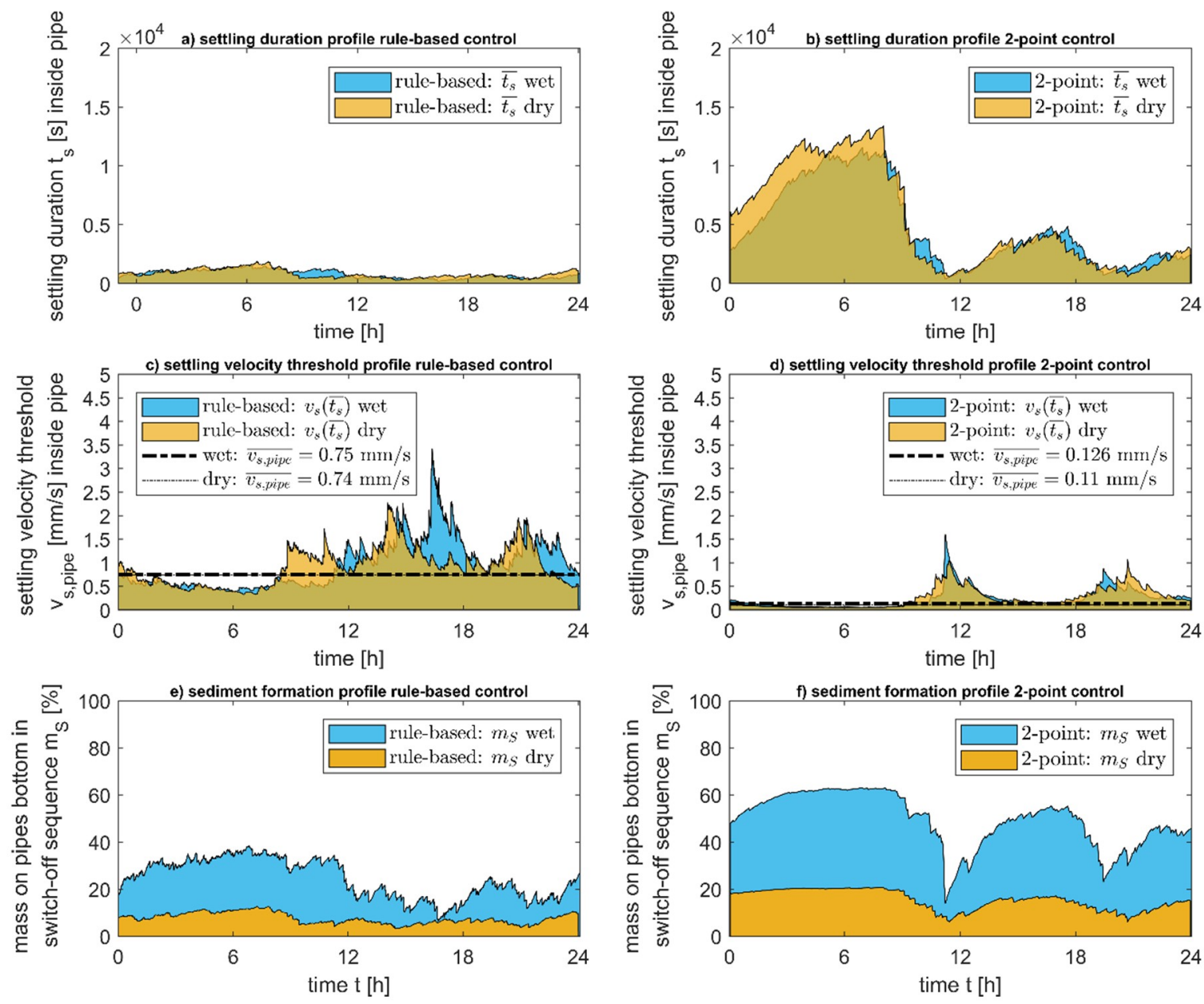

Figure 5. Results for sediment formation calculation after 2 years monitoring, average diurnal courses of the settling duration $(\mathbf{a}, \mathbf{b})$, settling velocity threshold $(\mathbf{c}, \mathbf{d})$ and settled mass $\left(m_{s}\right)$ on pipes bottom $(\mathbf{e}, \mathbf{f})$, for rule-based- $(\mathbf{a}, \mathbf{c}, \mathbf{e})$ and two-point control $(\mathbf{b}, \mathbf{d}, \mathbf{f})$.

Both settling duration profiles (dry and wet) in the two-point control (upper right plot) show the invert course of a typical sewage inflow for an urban PS. This course is still in existence in rule-based mode (upper left plot), but because of the formulated control rules significantly smoothed. It results in reduced settling sequences, primarily during phases of low inflow (21:00 to 09:00 and in the afternoon). Pump pauses of $2.5 \mathrm{~h}$ during the night were reduced to $\approx 40 \mathrm{~min}$ by the rule-based control. Besides, it leads to a more balanced feed of the wwtp, by a significant reduction of peak loads.

The $v_{s}$ threshold profiles are changing accordingly. Consistently, higher values resulting, with $v_{\text {s,pipe }} \geq 0.5 \mathrm{~mm} / \mathrm{s}$ in the night phases (while $<0.1 \mathrm{~mm} / \mathrm{s}$ in two-point control). From $\approx 09: 00$ to 23:00 $v_{\text {s, pipe }}$ does not fall below $0.74 \mathrm{~mm} / \mathrm{s}$, with peaks up to $2.25 \mathrm{~mm} / \mathrm{s}$ in the afternoon. Under combined 
inflow, nearly the same $v_{\text {s,pipe }}$ profile occurs, with peaks of $3.5 \mathrm{~mm} / \mathrm{s}$ in the afternoon. High $v_{\text {s,pipe }}$ values in two-point mode were only reached during phases of high inflow, especially under combined inflow with peaks up to $1.75 \mathrm{~mm} / \mathrm{s}$. However, higher $v_{\text {s,pipe }}$ values under combined inflow (for both control modes) are counteracted by the faster settling characteristics during rain events. The respective sediment formation profiles clearly shows this situation. The sediment formation is dominated by the settling characteristics of the sewage.

Figure 5, third row shows the effectiveness of the control rules, especially under combined inflow. The peaks of the sediment formation could be reduced from $m_{s}=63 \%$ (two-point control) to $m_{s}=$ $39.4 \%$ (rule-based control). Assuming the TSS content from

Table 2 for combined inflow, the deposit's amount, inside the whole pipe, decreases here from $\approx 398 \mathrm{~kg}\left(A_{\text {pipe }} \times l_{\text {pipe }} \times T S S_{\text {wet }} \times 0.63\right)$ to $\approx 240 \mathrm{~kg}(\ldots \times 0.394)$ by $158 \mathrm{~kg}$. In contrast, the peak deposit's decrease for dry weather inflow from $\approx 93 \mathrm{~kg}\left(\ldots \times T S S_{d r y} \times 0.2\right)$ to $\approx 70 \mathrm{~kg}(\ldots \times 0.156)$ by only $23 \mathrm{~kg}$. The difference in the control modes becomes clearer with the mean mass on pipes bottom: under rule-based control the mean mass calculates to $7.5 \%$ (dry weather inflow) and $24.2 \%$ (wet weather inflow), while under two-point control $15.4 \%$ of the initial TSS content reaching the pipes bottom under dry weather inflow and $49.3 \%$ under combined inflow. On average, the sediment formation is halved by the rule-based control.

The timing of the peaks are marginally affected by the control modes (06:51 and 06:57 for combined inflow and 07:51 and 08:04 for dry weather inflow). So, the sediment formation (and the risk of blockages) is at its maximum in the morning, just before the feed to the PS rises again.

Conversely, the sediment formation is at its minimum at a high dry weather feed (e.g., 21:00 and 20:50). The constellation of a slow settling sewage and short pump pauses leads to weak deposit's. Only $16.4 \mathrm{~kg}$ reaching the bottom of the pipe in rule-based $\left(\ldots \times T S S_{d r y} \times 0.036\right)$ mode and $27.6 \mathrm{~kg}$ in two-point control $\left(\ldots \times T_{S S} d r y \times 0.06\right)$.

Summarized, the expected reduction of the sediment formation, from two-point to rule-based control, could be verified by linking the experimental settling characteristics to the high-resolution pumping data. It allows detailed statements about the diurnal sediment formation, which helps to improve the energy savings, as well as the more balanced feed to the wwtp, over $24 \mathrm{~h}$.

\subsection{Verification by Calculated Deposit's Height}

To ensure a trouble-free sediment transport beyond $24 \mathrm{~h}$, the pipe curve was determined in a daily interval, using Equation (12). Subsequent, the calculation of the deposit's height $h_{s}$, by Equation (13), shows the sediment layer thickness over the studied period of 2 years, see Figure 6.

The mean deposit's height in rule-based mode was calculated to $=0.137 \mathrm{~m}$, while for two-point control to $0.174 \mathrm{~m}$. Split into dry and combined inflow, the mean deposit's height results in: rule-based dry $h_{s}=0.1375 \mathrm{~m}$, combined $h_{s}=0.1372 \mathrm{~m}$, two-point dry $h_{s}=0.1762 \mathrm{~m}$, combined $h_{s}=0.1721 \mathrm{~m}$. In rule-based mode, $h_{s}$ is significantly reduced, due to longer pump intervals.

However, in both control modes the average deposit's height under dry weather flow is higher compared to combined inflow. As seen in Figure 6, the rain events affecting $h_{s}$. Sediments washed-off from main roads or eroded inside an upstream sewer spilled to the PS, changing the settling characteristics and increasing the deposit's height long lasting. Apparently, the sediments height increases especially the day after a rain event. Figure 7 shows the change of the deposit's height by specific rain events for both control modes. The deposit's height increases with rain events (at day 0), but especially after intense ones with reaching its peak one day after the rain event (day one). Within the two-point control, the deposit's change at day 0 is at $+5 \mathrm{~cm}$, while one day after this change is at +5.5 to $6 \mathrm{~cm}(0.5 \mathrm{~cm}$ to $1 \mathrm{~cm}$ further increase to day 0$)$. On the following days, $h_{s}$ decreases slowly $\left(-3 \mathrm{~cm}\right.$ to day one). However, $h_{s}$ is still higher compared to the day before the rain event $(+3 \mathrm{~cm})$. $h_{s}$ at day 0 is reduced to $+2 \mathrm{~cm}$, while one day after a rain event $h_{s}$ increases again by $1 \mathrm{~cm}(+3 \mathrm{~cm}$ in total). On day $2 h_{s}$ decreases by $2 \mathrm{~cm}$, but is still $1 \mathrm{~cm}$ higher to the initial value. So, the $h_{s}$ increase is 
halved by the control rules (if inflow > optimal flow, then operate at inflow) and the main effect itself is limited to day one after rain events.
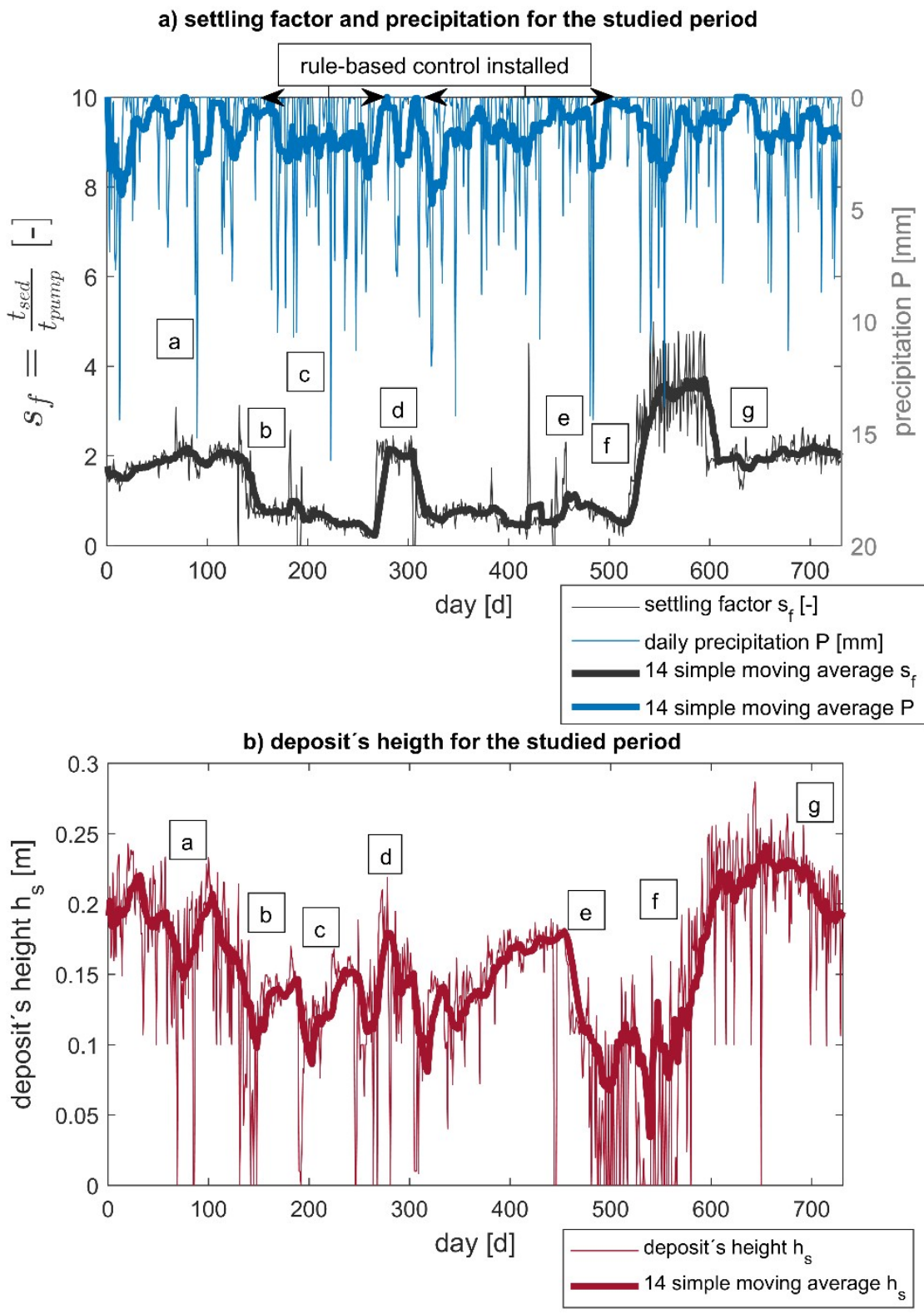

Figure 6. Results for calculation of the deposit's height after 2 years monitoring, settling factor $s_{f}(-)$ as ratio between the daily settling and pump duration and precipitation $P(\mathrm{~mm} / \mathrm{d})(\mathbf{a})$ and deposit's height $h_{s}(\mathrm{~m})$ including simple moving average over $14 \mathrm{~d}(\mathbf{b})$. a) significant increase of $h_{s}$ after intense rain $(15.2 \mathrm{~mm} / \mathrm{d}), \mathrm{b}) h_{s}$ reduced by parallel pumping (high $\left.\left.s_{f}\right), \mathrm{c}\right)$ increased $h_{s}$ after intense rain $(16.2 \mathrm{~mm} / \mathrm{d}$ ) in rule based mode, d) increased $h_{S}$ after re-installing two-point control in parallel with intense rain (33mm $/ 5 \mathrm{~d})$, e) decrease of $h_{s}$ by parallel pumping after long rule-based period with smooth $h_{s}$ increase, f) fast increase of $h_{s}$ after re-installing two-point control, g) $h_{s}$ normalized under two-point control mode to initial values. 

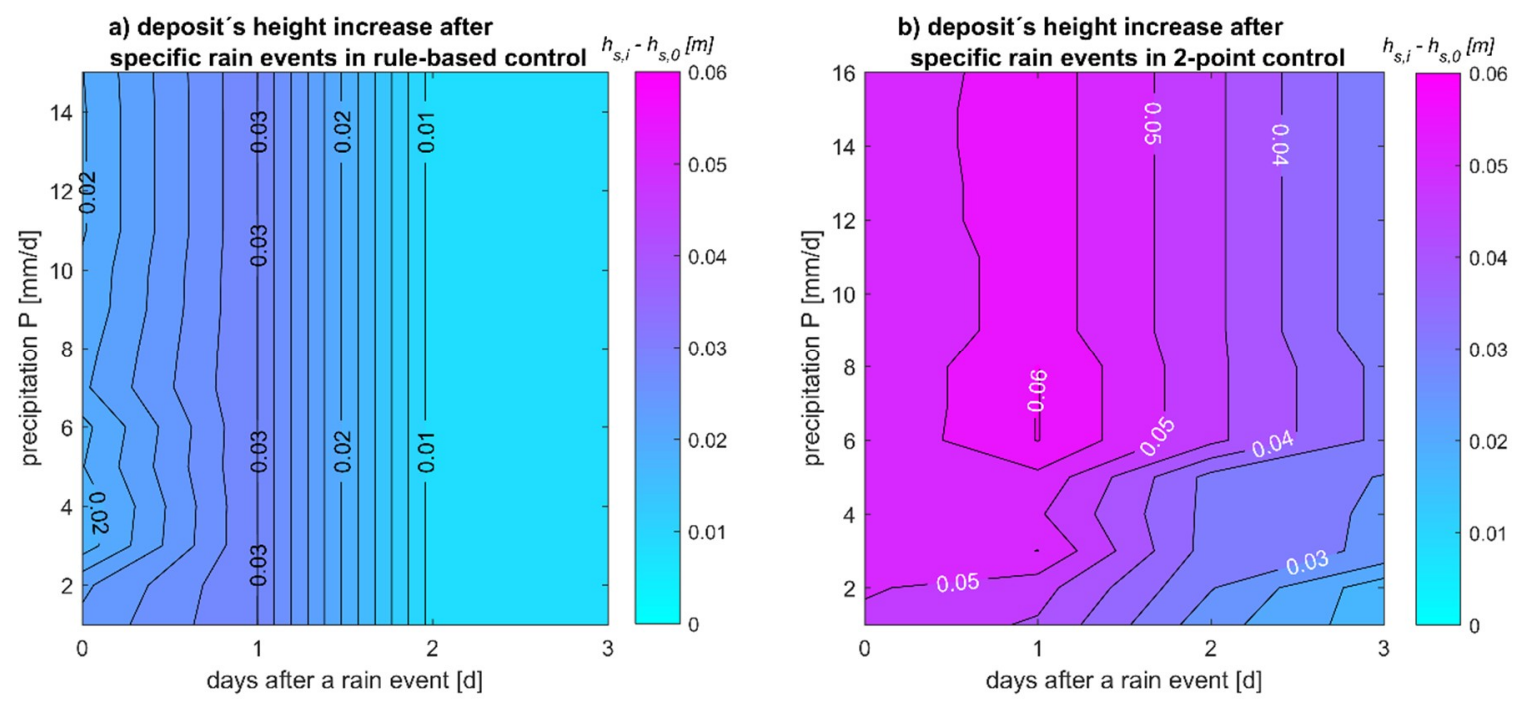

Figure 7. Results for the calculation of the delayed increase of the deposit's height $h_{s}$ inside the pressure pipe after specific rain events for rule-based (a) and two-point control (b).

As the rain events affecting $h_{s}$ in both control modes up to several days, there are two fundamental findings: (i) washed-off particles entering the upstream sewer were not entirely spilled to the PS within the storm flow. Deposited particles in the upstream links are then spilled progressively to the PS, which creates the further increase at day one after the rain event. This effect is significantly reduced in rule-based mode. (ii) Slowly decrease of $h_{s}$ starts after peak $h_{s}$ increase reached at day one after a rain event, independently to the intensity of the event. Due to a stronger $h_{s}$ increase in two-point control, this decrease phase lasts longer compared to rule-based mode. This long lasting change of $h_{s}$ leads to a higher power consumption, due to a reduced cross section.

Next to the evidence of a significantly reduced settling potential, the gained information can be used to solve typical problems in the operation of wastewater facilities. As an example: To overcome increased sedimentation risk, operators often flush pipes randomly. A more targeted pipe flushing is more effective and efficient. Based on the discussed findings, pipe flushing is optimal on day two after a rain event (with no regard to the intensity). However, even after long periods without pipe flushing (see point e in Figure 6), priory deposited particles due to several rain events can easily be removed by parallel pumping.

The calculation of the deposit's height clearly shows, that a long term energy saving pumping operation does not lead into an increased sedimentation risk, compared to a conventional pumping operation. In turn, it even reduces the sediment formation significantly, next to the energy savings. This statement can be verified by the results of [25], where the erodibility of settled raw sewage sediments itself was investigated. The results show that under the energy-efficient control, a resuspension of particles can be guaranteed.

A comparison to the literature regarding the monitoring of sediment heights is hardly available, thus the investigations mainly concentrating on open channel flow, e.g., [26,27]. Furthermore the used techniques, such as imaging techniques or ultrasonic sensors [26] or sonar devices [27], differ greatly to the presented approach.

\section{Conclusions}

The paper presents settling experiments of municipal raw sewage, their interpretation and their application for the investigation of the sediment formation for an energy-efficient controlled pumping system. The presented results were verified by an indirect determination of the deposit's height inside the pressure pipe. Based on the above discussed findings, the following conclusions can be drawn: 
- The adapted experimental setup (VICAS/VICPOL-protocol) is robust and provides reproducible results;

- Settling behavior from dry to combined inflow changes significantly in medium speed classes;

- Pump pauses decrease/pump sequences increase from conventional two-point control to rule-based control;

- Rule-based mode allows higher threshold values of settling velocity, especially for combined inflow, followed by a significant reduction of the sediment formation;

- Pipe curve observation leads to reliable findings about the deposit's height;

- Daily variations in deposit's height were registered, but no significant increase in sedimentation risk.

Summarized, no disadvantages arise over a long period by installing the energy-efficient operation mode. On the contrary, the energy saving pumping operation even lead to a reduced sediment formation potential under the investigated conditions.

Advances in sewage transport, such as energy optimization, are often driven urban water models. Those numerical simulations need accurate calibration data. Providing precise data enables concise models and as a result more sustainable solutions to be designed. The presented experimental procedure and its subsequent calculation methods allow a precise determination of sedimentation data for raw sewage. It helps to characterize raw sewage more precisely and understand sedimentation processes in energy-optimized urban drainage systems. The published data is exemplary for a separate sewerage system (with storm runoff from main roads) in an urban region.

Author Contributions: Conceptualization, M.R., J.T., and T.K.; Data curation, M.R.; Formal analysis, M.R.; Funding acquisition, J.T.; Investigation, M.R.; Methodology, M.R.; Project administration, J.T.; Software, M.R.; Supervision, J.T.; Validation, M.R.; Visualization, M.R.; Writing—original draft, M.R.; Writing—review \& editing, J.T. and T.K.

Funding: The presented studies are supported by Deutsche Bundesstiftung Umwelt (DBU), Germany (AZ 32253/01).

Acknowledgments: The precipitation data used are available from Germany's national meteorological service (Deutscher Wetterdienst (DWD)), http:/ / www.dwd.de.

Conflicts of Interest: The authors declare no conflict of interest. The funders had no role in the design of the study; in the collection, analyses, or interpretation of data; in the writing of the manuscript, and in the decision to publish the results.

\section{References}

1. Knubbe, A.; Fricke, A.; Ecktädt, H.; Neymeyr, K.; Schwarz, M.; Traenckner, J. Energieeffizienter Betrieb von Abwasserfördersystemen. Energy-efficient strategies for wastewater pumping systems. gwf-Wasser | Abwasser 2014, 155, 640-646.

2. Deutsches Institut für Normung e.V. (DIN). Entwässerungssysteme außerhalb von Gebäuden, PumpsystemeTeil 2: Druckentwässerungssysteme; Deutsche Fassung EN 16932-2:2018. In Drain and Sewer Systems Outside Buildings-Pumping Systems-Part 2: Positive Pressure Systems; Beuth Verlag GmbH: Berlin, Germany, 2018.

3. Benoist, A.P.; Lijklema, L. Distribution of sedimentation rates of suspended solids and heavy metals in combined sewer overflows. Water Sci. Technol. 1990, 22, 61-68. [CrossRef]

4. Michelbach, S.; Woehrle, C. Settleable solids in a combined sewer system-Measurement, quantity, characteristics. Water Sci. Technol. 1992, 25, 181-188. [CrossRef]

5. Tyack, J.N.; Hedges, P.D.; Smisson, R.P.M. The relationship between settling velocity grading and the characteristics of the contributing catchment. Water Sci. Technol. 1996, 33, 135-142. [CrossRef]

6. Hedges, P.D.; Becker, F.A.; Smisson, R.P.M. The application of settling velocity as a parameter for characterising wastewater solids. Water Sci. Technol. 1998, 37, 45-52. [CrossRef]

7. Chebbo, G.; Gromaire, M.-C.; Lucas, E. Protocole VICAS: Mesure de la vitesse de chute des MES dans les effluents urbains. TSM. Techn. Sci. Methodes Génie Urbain Génie Rural 2003, A98, 39-49. 
8. Gromaire, M.C.; Kafi-Benyahia, M.; Gasperi, J.; Saad, M.; Moilleron, R.; Chebbo, G. Settling velocity of particulate pollutants from combined sewer wet weather discharges. Water Sci. Technol. 2008, 58, 2453-2465. [CrossRef]

9. Hasler, M. Field and Laboratory Experiments on Settling Process in Stormwater Storage Tanks. Diploma Thesis, INSA de Lyon, Villeurbanne, France, Graz University of Technology, Graz, Austria, 15 May 2007.

10. Li, Y.; Kang, J.-H.; Lau, S.-L.; Kayhanian, M.; Stenstrom, M.K. Optimization of Settling Tank Design to Remove Particles and Metals. J. Environ. Eng. 2008, 134, 885-894. [CrossRef]

11. Te Slaa, S.; van Maren, D.S.; He, Q.; Winterwerp, J.C. Hindered Settling of Silt. J. Hydraul. Eng. 2015, 141, 4015020. [CrossRef]

12. Chakraborti, R.K.; Kaur, J. Noninvasive Measurement of Particle-Settling Velocity and Comparison with Stokes' Law. J. Environ. Eng. 2014, 140, 4013008. [CrossRef]

13. Nikora, V.; Aberle, J.; Green, M. Sediment Flocs: Settling Velocity, Flocculation Factor, and Optical Backscatter. J. Hydraul. Eng. 2004, 130, 1043-1047. [CrossRef]

14. Shao, Y.; Yan, Y.; Maa, J.P.-Y. In Situ Measurements of Settling Velocity near Baimao Shoal in Changjiang Estuary. J. Hydraul. Eng. 2011, 137, 372-380. [CrossRef]

15. Yam, K.; Burns, A.D.; Ingham, D.B.; McCaffrey, W.D. Influence of Lift Force on the Settling Velocities of Rotating Particles in Two-Dimensional Shear Flow. J. Hydraul. Eng. 2013, 139, 1277-1285. [CrossRef]

16. Cheng, N.-S. Effect of Concentration on Settling Velocity of Sediment Particles. J. Hydraul. Eng. 1997, 123, 728-731. [CrossRef]

17. Wu, W.; Wang, S.S.Y. Formulas for Sediment Porosity and Settling Velocity. J. Hydraul. Eng. 2006, 132, 858-862. [CrossRef]

18. Camenen, B. Simple and General Formula for the Settling Velocity of Particles. J. Hydraul. Eng. 2007, 133, 229-233. [CrossRef]

19. Chebbo, G. Solides des Rejets Pluviaux Urbains: Caractérisation et Traitabilité. Ph.D. Thesis, Ecole Nationale des Ponts et Chaussées, Paris, France, 1992.

20. Chancelier, J.P.; Chebbo, G.; Lucas-Aiguier, E. Estimation of settling velocities. Water Res. 1998, 32, 3461-3471. [CrossRef]

21. Bertrand-Krajewski, J.-L. Détermination des Vitesses de Chute des Polluants en Phase Particulaire des Rejets Urbains par Ajustement Numérique de la Courbe M(t) Pour le Protocole VICTOR; INSA de Lyon-Laboratoire URGC Hydrologie Urbaine: Villeurbanne, France, 2001.

22. Deutsches Institut für Normung e.V. (DIN). Deutsche Einheitsverfahren zur Wasser-, Abwasser-und Schlammuntersuchung; Summarische Wirkungs-und Stoffkenngrößen (Gruppe H); Bestimmung des Gesamttrockenrückstandes, des Filtrattrockenrückstandes und des Glührückstandes (H 1) [German Standard Methods for the Examination of Water, Waste Water and Sludge; General Measures of Effects and Substances (Group H); Determination of the Total Solids Residue, the Filtrate Solids Residue and the Residue on Ignition (H 1)]; Beuth Verlag GmbH: Berlin, Germany, 1987.

23. Chebbo, G.; Gromaire, M.-C. VICAS-An Operating Protocol to Measure the Distributions of Suspended Solid Settling Velocities within Urban Drainage Samples. J. Environ. Eng. 2009, 135, 768-775. [CrossRef]

24. Krishnappan, B.G.; Exall, K.; Marsalek, J.; Rochfort, Q.; Kydd, S.; Baker, M.; Stephens, R.P. Variability of Settling Characteristics of Solids in Dry and Wet Weather Flows in Combined Sewers: Implications for CSO Treatment. Water Air Soil Pollut. 2012, 223, 3021-3032. [CrossRef]

25. Rinas, M.; Traenckner, J.; Koegst, T. Erosion characteristics of raw sewage: Investigations for a pumping station in northern Germany under energy-efficient pump control. Water Sci. Technol. 2018. [CrossRef]

26. Regueiro-Picallo, M.; Naves, J.; Anta, J.; Suárez, J.; Puertas, J. Monitoring accumulation sediment characteristics in full scale sewer physical model with urban wastewater. Water Sci. Technol. 2017, 76, 115-123. [CrossRef] [PubMed]

27. Lepot, M.; Pouzol, T.; Aldea Borruel, X.; Suner, D.; Bertrand-Krajewski, J.-L. Measurement of sewer sediments with acoustic technology: From laboratory to field experiments. Urban Water J. 2017, 14, 369-377. [CrossRef]

(C) 2018 by the authors. Licensee MDPI, Basel, Switzerland. This article is an open access article distributed under the terms and conditions of the Creative Commons Attribution (CC BY) license (http:// creativecommons.org/licenses/by/4.0/). 